\title{
Magnetic Properties of Mechanically-Alloyed Sm-Co Nanophase Hard Magnets
}

\author{
K. Gallagher, M. Venkatesan, and J. M. D. Coey, Member, IEEE
}

\begin{abstract}
Highly coercive $\mathrm{Sm}_{14} \mathrm{Co}_{86}$ powders were prepared by mechanical alloying with a view to enhance the high temperature magnetic properties by optimizing the annealing conditions. The powders were annealed in quartz tubes with a continuous vacuum of $\sim 10^{-6}$ mbar at different temperatures. $\mathrm{X}$-Ray diffraction studies confirmed the formation of a disordered 2:17 phase. DTA measurement on the as-milled amorphous powders revealed a single crystallization event at around $500{ }^{\circ} \mathrm{C}$. Magnetic measurements showed room temperature coercivities of at least $1 \mathrm{~T}$ and Curie temperatures around $820^{\circ} \mathrm{C}$. The behavior of the initial magnetization curve lies in between those observed for low $H_{c} 2: 17$ precipitation hardened magnets and $\mathrm{SmCo}_{5}$ or $\mathrm{Nd}_{2} \mathrm{Fe}_{14} \mathrm{~B}$ magnets. The magnitude of coercivity is found to be sensitive to annealing temperature. The detailed comparison of magnetic properties with annealing conditions will be presented.
\end{abstract}

Index Terms-High temperature applications, mechanically alloyed materials, rare earth permanent magnets, $\mathrm{Sm-Co}$ based permanent magnets.

\section{INTRODUCTION}

$\mathbf{I}$ $\mathrm{N}$ BOTH the United States and Europe, the search for new high temperature permanent magnets has become a key issue which has lead to resurgence in interest in $\mathrm{Sm}_{2} \mathrm{Co}_{17}$ type magnets. The normal approach to development of coercivity, $H_{c}$, in these precipitation-hardened bulk magnets is to develop nanophase cellular microstructures with cell walls that act as pinning sites [1]. In mechanically alloyed magnetic materials, additional crystallographic defects are introduced which lead to a higher coercivity [2], while remanence enhancement has also been observed [3]. Extensive studies were performed on Sm-Co nanocrystalline powders prepared by mechanical alloying [4], but they did not examine high temperature properties of the materials. The purpose of our current work is to enhance the high temperature properties of $\mathrm{Sm}_{14} \mathrm{Co}_{86}$, which in an intermediate composition between the $\mathrm{SmCo}_{5}$ and $\mathrm{Sm}_{2} \mathrm{Co}_{17}$ compositions, through optimization of annealing temperature.

\section{EXPERIMENTAL}

$\mathrm{Sm}_{14} \mathrm{Co}_{86}$ (nominal composition) samples were mechanically alloyed from a mixture of $\mathrm{SmCo}_{5}$ and $99.8 \%$ pure Co powder. The $\mathrm{SmCo}_{5}$, obtained from Less Common Metals, Merseyside, England in ingot form, was broken up and crushed

Manuscript received October 13, 2000.

This material is based upon work supported under a National Science Foundation Graduate Fellowship (KG). This work forms part of the HITEMAG project, an EU growth program.

The authors are with the Physics Department, Trinity College, Dublin 2, Ireland (e-mail: \{kagallag; venkatem; jcoey $\} @$ tcd.ie).

Publisher Item Identifier S 0018-9464(01)06876-5. under an argon atmosphere before milling. The milling was carried out under an argon atmosphere for 12 hours in a high energy Spex 8000 mixer/mill with a ball to powder charge ratio of $9.3: 1$.

As-milled powders were subjected to a subsequent annealing at various temperatures between $650{ }^{\circ} \mathrm{C}$ and $850{ }^{\circ} \mathrm{C}$. The annealing treatment was carried out in quartz tubes which were continuously evacuated during annealing to maintain a vacuum on the order of $10^{-6}$ mbar. Two different methods for annealing were tested. In method I, the furnace was preheated to the desired temperature and then the sample was pushed into the hot zone of the furnace. After the desired length of time, the tube was removed from the hot furnace and allowed to cool in air (with the sample still under vacuum). In method II, the tube was pushed into the furnace at room temperature and then heated at $10{ }^{\circ} \mathrm{C} / \mathrm{min}$ to the desired temperature. The tube was held at the chosen temperature for the desired length of time, and then cooled inside the furnace at a rate of $5{ }^{\circ} \mathrm{C} / \mathrm{min}$.

Chemical and oxygen/nitrogen analysis confirmed that the contamination of the samples was negligible, with $<5 \mathrm{wt} \% \mathrm{Fe}$, $<0.1 \mathrm{wt} \%,<0.06 \mathrm{wt} \% \mathrm{~N}_{2}$, and $<0.25 \mathrm{wt} \% \mathrm{O}_{2}$. The $\mathrm{Sm}_{14} \mathrm{Co}_{86}$ nominal composition samples were shown to actually contain $26.5 \mathrm{wt} \% \mathrm{Sm}$ after milling and annealing, rather than $29.4 \mathrm{wt} \%$, giving an actual composition closer to $\mathrm{Sm}_{12.4} \mathrm{Co}_{87.6}$.

Powder x-ray diffraction (XRD) was carried out on both as-milled and annealed powders using a Siemens D500 XRD with $\mathrm{Cu}-\mathrm{K} \alpha$ radiation. Crystallization behavior of the as-milled powders was studied using a Stanton-Redcroft DTA with a heating rate of $10{ }^{\circ} \mathrm{C} / \mathrm{min}$ under Ar flowing at $25 \mathrm{~cm}^{3} / \mathrm{min}$. Scanning Electron Microscopy (SEM) was used to study powder morphology. Samples for room temperature magnetic hysteresis measurements were prepared by mixing approximately $20 \mathrm{mg}$ of annealed powder with Lecoset 7007 cold curing resin inside a $4 \mathrm{~mm}$ by $4 \mathrm{~mm}$ cylindrical Perspex bucket. After the epoxy had cured, samples were magnetized in an $8 \mathrm{~T}$ pulsed field before measuring hysteresis loops in a vibrating sample magnetometer up to $1.0 \mathrm{~T}$ applied field. Measurement of hysteresis loops in fields greater than $1.1 \mathrm{~T}$ was carried out using an extraction magnetometer.

\section{RESULTS AND DISCUSSION}

Typical powder x-ray diffraction patterns for the as-milled materials showed only a broad hump around $44^{\circ} 2 \theta$, as shown in Fig. 1. This is indicative of an amorphous structure. SEM showed the powder particles to be roughly spherical, with a rough surface. Individual particles range from a few micrometers in size up to $20 \mu \mathrm{m}$, while agglomerations of particles could 


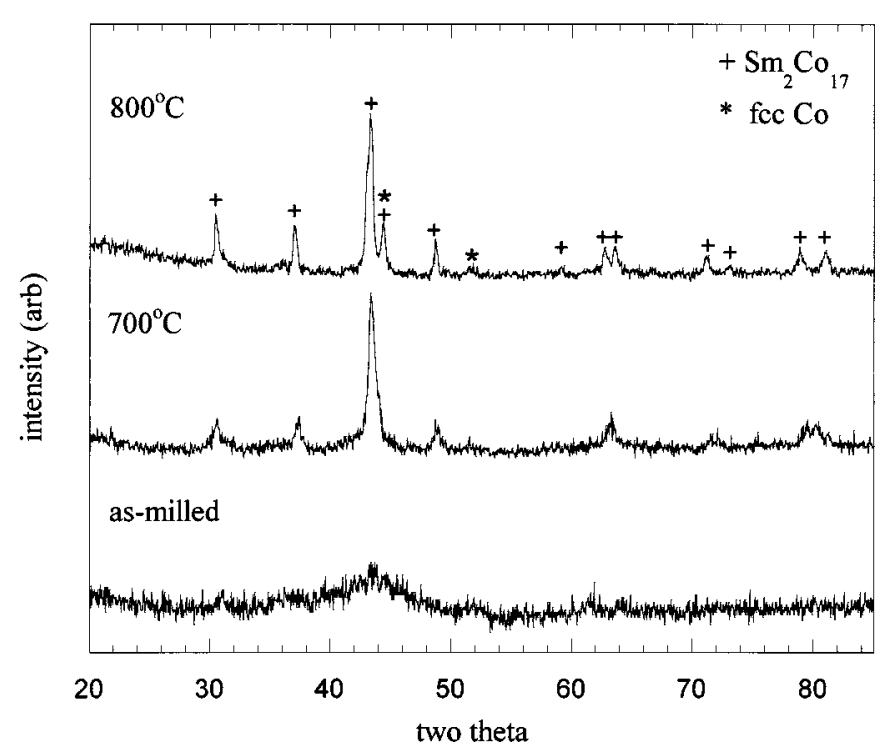

Fig. 1. Typical $\mathrm{Cu}-\mathrm{K} \alpha \mathrm{X}$-Ray diffraction patterns for as-milled $\mathrm{Sm}_{14} \mathrm{Co}_{86}$ samples and samples annealed at $700^{\circ} \mathrm{C}$ and $800^{\circ} \mathrm{C}$. As-milled samples exhibit an amorphous structure which crystallizes to a disordered $\mathrm{Sm}_{2} \mathrm{Co}_{17}$ structure at annealing temperatures $\geq 500^{\circ} \mathrm{C}$. At annealing temperatures $\geq 800^{\circ} \mathrm{C}$, there is Sm loss which is evidenced by the appearance of fcc Co peaks in the XRD patterns.

be up to $50 \mu \mathrm{m}$ in size. This morphology is consistent with previous observations for mechanically alloyed materials [5], [6].

The DTA trace on heating the as-milled $\mathrm{Sm}_{14} \mathrm{Co}_{86}$ displayed a peak at around $440{ }^{\circ} \mathrm{C}$, where the amorphous phase undergoes crystallization. X-Ray diffraction of samples annealed just above this temperature showed this peak to be indicative of crystallization of $\mathrm{Sm}_{2} \mathrm{Co}_{17}$ from the amorphous material.

The X-Ray diffraction pattern for the sample annealed at $700{ }^{\circ} \mathrm{C}$, shown in Fig. 1, is typical of those for samples annealed at $650{ }^{\circ} \mathrm{C} \leq T_{a n n}<800{ }^{\circ} \mathrm{C}$. The pattern is characteristic of $\mathrm{Sm}_{2} \mathrm{Co}_{17}$, in that it contains only the main reflections which are shared by both rhombohedral $\left(\mathrm{Th}_{2} \mathrm{Zn}_{17}\right)$ type and hexagonal $\left(\mathrm{Th}_{2} \mathrm{Ni}_{17}\right)$ type phases. The samples probably consist of a single phase with random sections of rhombohedral and hexagonal stacking sequences. For samples annealed at $T_{\text {ann }} \geq 800{ }^{\circ} \mathrm{C}$, there is a loss of $\mathrm{Sm}$ due to vaporization. This is evidenced by a metallic coating on the quartz tube after annealing and the appearance of small peaks around $45^{\circ}$ and $52^{\circ} 2 \theta$ in the X-Ray diffraction pattern (Fig. 1). These peaks are characteristic of fcc Co. Hysteresis loops for the samples annealed at $T_{a n n} \geq 800{ }^{\circ} \mathrm{C}$ indicate that the fcc Co phase is exchange coupled to the $\mathrm{Sm}_{2} \mathrm{Co}_{17}$ phase. The Curie temperature $\left(T_{c}\right)$ of the samples, determined by magnetic measurements, is around $820^{\circ} \mathrm{C}$.

Hysteresis loops comparing the two annealing methods are shown in Fig. 2. Both samples were annealed at $750{ }^{\circ} \mathrm{C}$, in method I for $30 \mathrm{~min}$, but for only $15 \mathrm{~min}$ in method II. The sample annealed with method II shows a much larger coercivity than the sample annealed with method I.

After choosing method II as the better annealing method, a study of the effect of annealing temperature on the magnetic properties of mechanically alloyed $\mathrm{Sm}_{14} \mathrm{Co}_{86}$ was carried out. Samples were annealed using method II at temperatures $650^{\circ} \mathrm{C}$ $\leq T_{a n n} \leq 850^{\circ} \mathrm{C}$ for 15 minutes. $H_{c}$ peaks for $T_{a n n}$ between

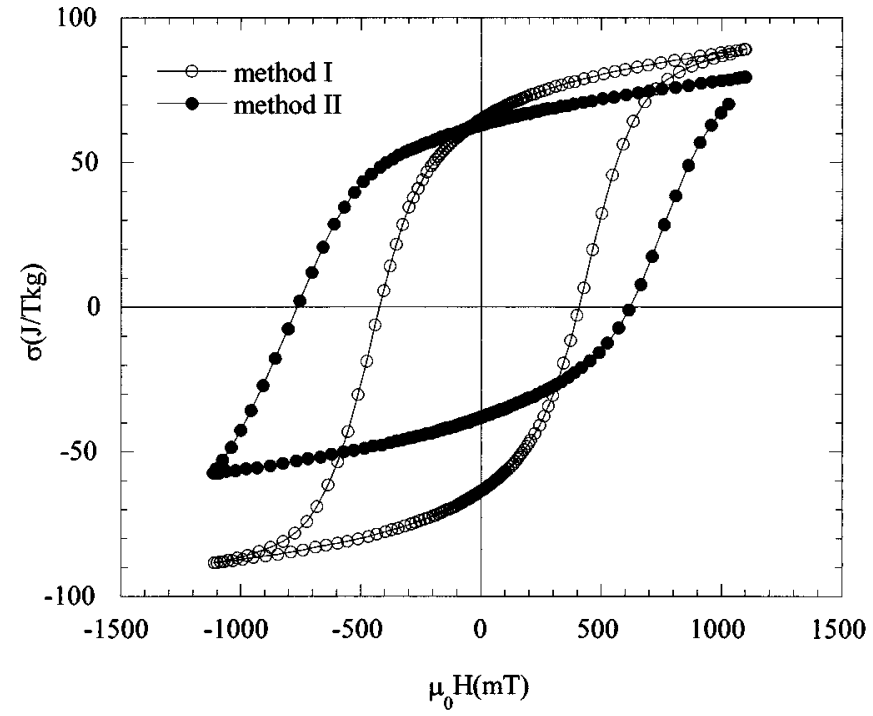

Fig. 2. Hysteresis loops comparing two different annealing routes for mechanically alloyed $\mathrm{Sm}_{14} \mathrm{Co}_{86}$. In both methods the samples were loaded into a quartz tube which was continuously evacuated during annealing to a pressure of $10^{-6}$ mbar. In method I, the furnace was preheated to $750^{\circ} \mathrm{C}$ and then the sample was pushed into the hot furnace. After $30 \mathrm{~min}$, the tube was removed from the hot furnace and allowed to cool in air (with the sample still under vacuum). In method II, the tube was pushed into the cool (room temperature) furnace and then heated at $10^{\circ} / \mathrm{min}$ to $750^{\circ} \mathrm{C}$. The tube was held at temperature for the desired length of time, and then cooled inside the furnace at a rate of $5 \% \mathrm{~min}$

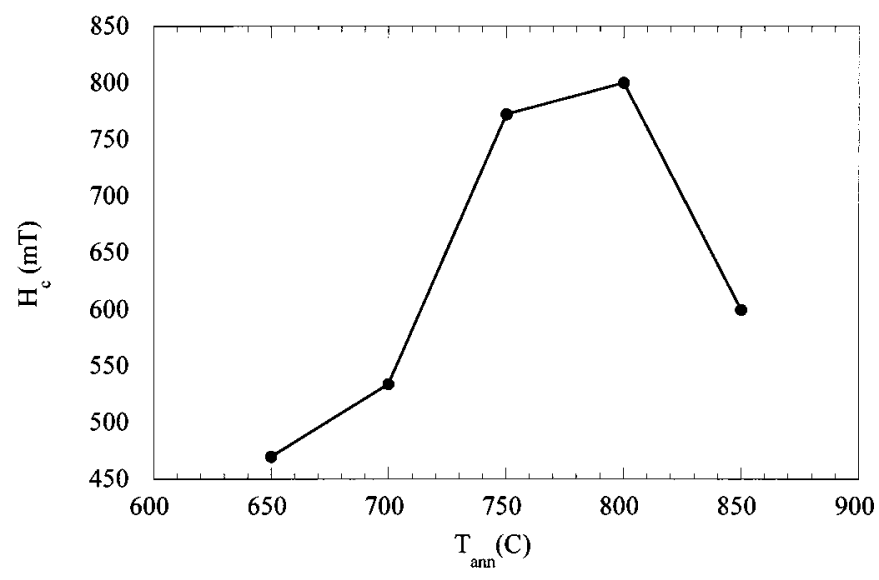

Fig. 3. Magnetic properties of mechanically alloyed $\mathrm{Sm}_{14} \mathrm{Co}_{86}$ as a function of annealing temperature.

$750{ }^{\circ} \mathrm{C}$ and $800^{\circ} \mathrm{C}$ (Fig. 3). This behavior suggests that the optimum temperature range for annealing to develop a microstructure with high coercivity lies between $750{ }^{\circ} \mathrm{C}$ and $800{ }^{\circ} \mathrm{C}$.

One sample was annealed twice using method II with $T_{a n n}=700^{\circ} \mathrm{C}$ for $30 \mathrm{~min}$ each time. Interestingly, this sample presents a high coercivity of $1.1 \mathrm{~T}$, shown by the hysteresis loop in Fig. 4. The behavior of the initial magnetization curve lies in between those observed for low $H_{c} 2: 17$ precipitation hardened magnets and $\mathrm{SmCo}_{5}$ [8], suggesting a mixture of pinning-type and nucleation-type behavior. The enhanced $M_{r} / M_{s}$ ratio $(>0.5)$ indicates the existence of intergrain exchange interactions among the fine grains [7]. In addition, the hysteresis loop shows a smooth demagnetization curve, indicating a very fine and uniform grain size in the samples. 


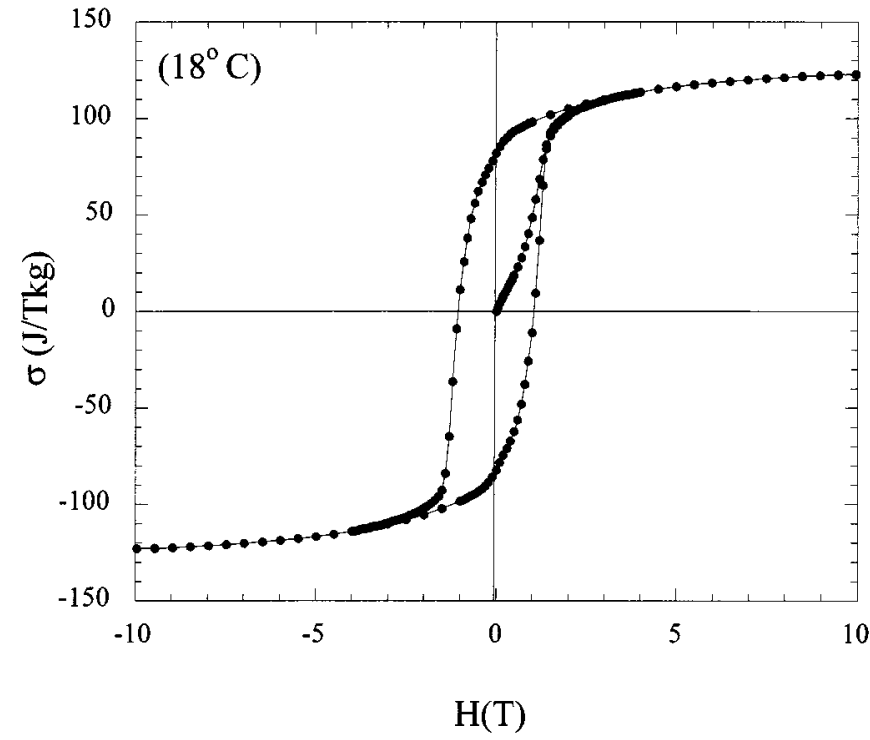

Fig. 4. Hysteresis loop for $\mathrm{H}(\mathrm{T})$ mechanically alloyed $\mathrm{Sm}_{14} \mathrm{Co}_{86}$ annealed twice at $700{ }^{\circ} \mathrm{C}$ for $30 \mathrm{~min}$ using annealing method II, which involves slow heating and cooling steps.

\section{CONCLUSIONS}

Our current studies show that the coercivity of mechanically alloyed $\mathrm{Sm}_{14} \mathrm{Co}_{86}$ powders can be dramatically increased by optimizing the annealing temperature and the method of annealing. The as-milled powder particles were roughly spherical and chemical analysis showed negligible contamination from the milling container and balls and oxygen. The as-milled powders crystallized to a disordered $\mathrm{Sm}_{2} \mathrm{Co}_{17}$ structure at annealing temperatures less than $800{ }^{\circ} \mathrm{C}$. Above that temperature there was vaporization of $\mathrm{Sm}$, as evidenced by the appearance of fcc Co peaks in the X-Ray diffraction pattern.

Two different annealing routes were tested and it was found that an annealing process starting with a slow heat and ending with a slow cool was the better route to optimize the microstructure. A study using the slow heat/slow cool method and varying the annealing temperature showed that the best $H_{c}$ is achieved with annealing temperatures between $750{ }^{\circ} \mathrm{C}$ and $800{ }^{\circ} \mathrm{C}$.

A coercivity of $1.1 \mathrm{~T}$ was achieved for a mechanically alloyed $\mathrm{Sm}_{14} \mathrm{Co}_{86}$ sample which had been annealed twice at $700{ }^{\circ} \mathrm{C}$ for 30 min with a slow heat and slow cool each time. This indicates that longer annealing times and/or a second annealing step may be necessary for coercivity development in these materials.

\section{ACKNOWLEDGMENT}

The authors thank Dr. N. Dempsey of the Laboratoire Louis Néel, Grenoble, France, for the magnetic measurements in fields greater than $1.1 \mathrm{~T}$.

\section{REFERENCES}

[1] G. C. Hadjipanayis, "Nanophase hard magnets," J. Magn. Magn. Mat., vol. 200, pp. 373-391, 1999.

[2] S. K. Chen, J. L. Tsai, and T. S. Chin, "Coercivity and transmission electron microscopy study of nanocomposite Sm-Co powders by mechanical alloying," J. Appl. Phys., vol. 81, pp. 5631-5633, 1997.

[3] J. Ding, Y. Liu, P. G. McCormick, and R. Street, "Remanence enhancement in isotropic Sm-Co powders," J. Magn. Magn. Mat., vol. 123, pp. L239-L242, May 1993.

[4] P. G. McCormick, W. F. Miao, P. A. I. Smith, J. Ding, and R. Street, "Mechanically alloyed nanocomposite magnets," J. Appl. Phys., vol. 83, pp. 6256-61, 1998 .

[5] P. J. McGuiness and S. Kobe, "Enhanced remanence behavior in mechanically alloyed $\mathrm{SmCo}_{5}$," J. Alloys and Compounds, vol. 281, pp. 23-26, 1998.

[6] G. B. Schaffer and P. G. McCormick, "Reduction of metal oxides by mechanical alloying," Appl. Phys. Lett., vol. 55, pp. 45-46, July 1989.

[7] R. Fisher and H. Kronmüller, "The role of the exchange interaction in nanocrystalline isotropic $\mathrm{Nd}_{2} \mathrm{Fe}_{14} \mathrm{~B}$ magnets," J. Magn. Magn. Mat., vol. 191, pp. 225-233, 1999.

[8] K. J. Strnat, "Rare-earth-cobalt permanent magnets," in Ferromagnetic Materials. Amsterdam: North-Holland, vol. IV. 